\title{
La traducción del japonés al español: consideraciones desde una concepción cognitivista y cultural de la Lingüística
}

\author{
María Amparo MonTANER MontaVA \\ Universitat de València \\ Maria.A.Montaner@uv.es
}

Recibido: 5 de diciembre de 2011

Aceptado: 27 de noviembre de 2012

\section{RESUMEN}

Cada vez más los estudios de Traducción requieren una visión amplia de la Lingüística, que considere la cognición y la cultura como pilares de la comunicación. Desde esa perspectiva, en la primera parte del trabajo se van a presentar diversas consideraciones que un traductor debería tener en cuenta para trabajar con lenguas sin parentesco tipológico y que provienen de culturas tan distintas como la japonesa y la española. El segundo apartado se dedica a los problemas de la traducción literaria que provienen del lenguaje. Se analizan ejemplos de traducción de poesía.

Palabras clave: Problema, traducción, Lingüística, literatura, español, japonés.

\section{Translation from Japanese to Spanish: Considerations from a Cognitive} and Cultural Approach to Linguistics

\begin{abstract}
Translation Studies require a wide conception of Linguistics, which considers Cognition and Culture as a tool in the communication process. From this point of view, the first section of this paper includes several considerations that a translator should bear in mind in order to work with languages that are not typologically and culturally related, such as Japanese and Spanish. The last section discusses some linguistic problems of literary translation, analysing examples of tanslation of poetry.
\end{abstract}

Keywords: problem, translation, linguistics, literature, Spanish, Japanese.

Sumario: 1. Propósito. 2. Consideraciones lingüísticas en la traducción del japonés al español. 2.1. Decisiones relacionadas con la gramática. 2.2. Decisiones relacionadas con el léxico. 2.3. Decisiones comunicativas. 3. Problemas lingüísticos en la traducción literaria del japonés al español. 


\section{Propósito ${ }^{1}$}

Si la Lingüística merece tener un espacio en el seno de la Traductología, debe ser desde una concepción amplia de la misma, que asuma que la cultura y la cognición constituyen un marco que articula y modela el lenguaje. En ese sentido, los estudios de Traductología ${ }^{2}$ requieren cada vez más una visión amplia de la Lingüística, que considere la cognición y la cultura como pilares de la comunicación interlingüística e intercultural. Desde esta perspectiva se van a presentar diversas consideraciones que un traductor debería tener en cuenta para traducir adecuadamente lenguas que no guardan relación tipológica y que provienen de culturas tan distintas como la japonesa y la española.

Se ha hablado frecuentemente de la traducción como de un proceso de toma de decisiones, $\mathrm{y}$ en estas páginas se va a adoptar este planteamiento para valorar algunas de las decisiones formales que se ve obligado a tomar el traductor en su tarea cuando se enfrenta a problemas lingüísticos. Se seleccionarán problemas relacionados con la gramática, el léxico y el contexto.

La última sección se dedica a problemas de la traducción literaria derivados de características lingüísticas. En ella se comentarán lingüísticamente traducciones de poesía del japonés al español.

\section{Consideraciones lingüísticas en la traducción del japonés al español}

\subsection{Decisiones relacionadas con la gramática}

Las diferencias gramaticales entre lenguas son algo común. Sin embargo, las diferencias aparentemente gramaticales pero que implican cambios de sentido ya representan un mayor problema para el traductor. Un buen ejemplo de esta problemática es el que representan las construcciones, que principalmente transmiten un significado determinado pero que además aportan secundariamente matices de sentido añadidos.

Esta situación teóricamente se puede explicar mediante un enfoque construccional como el que representa la Gramática de Construcciones, porque según este modelo, de índole cognitivista, existe un significado aportado por la propia construcción, más allá de la suma de los significados de los elementos que la componen. Consideramos que por esa razón muchas veces hay matices difíciles de mantener en una traducción. Si se tradujeran habría que decir directamente lo que en el original solamente se deriva del uso de una construcción, lo cual suele resultar formalmente

\footnotetext{
${ }^{1}$ Este trabajo se ha realizado dentro del proyecto de Investigación concedido por el Ministerio de Educación, con el nombre Verificación experimental de la conciencia del habla examinada mediante pruebas realizadas a hispanohablantes (FFI 2008-05248)

${ }^{2}$ Numerosos estudiosos, como Ó. Díaz Fouces (2004) o R. Muñoz (1995) han defendido el interés de una concepción amplia de la Lingüística en los Estudios de Traducción.
} 
menos conveniente que la simple omisión de tales matices. A continuación se examinarán ejemplos de cuatro construcciones del japonés sin equivalente en español, imposibles de traducir de forma absolutamente equivalente.

Ejemplo 1: Yuki wa Taroo ni isu o warareta

Nombre-tópico-nombre-agente-silla-acusativo-verbo (pasiva)

Traducción aproximada: Yuki fue afectada negativamente porque Taro rompió la silla.

La construcción que aparece en este ejemplo no se puede traducir literalmente. En ella aparece Yuki como tópico, Taroo ni es semánticamente un agente, isu o es el objeto directo, semánticamente objeto afectado y el verbo romper está en forma pasiva.

En japonés, el participante que aparece como tópico, Yuki wa (Yuki), se ve afectado negativamente por el resultado de la acción verbal, matiz que no se puede traducir fácilmente al español, pero que se deduce de la construcción japonesa, sin necesidad de decirlo directamente. En español sencillamente no existe una construcción que combine un verbo en forma pasiva y un objeto directo, y que presente como tópico a la persona relacionada con lo que le ha ocurrido al participante que aparece como objeto directo. Es esta construcción japonesa la que aporta el matiz de afección para la persona cuyo objeto se ve afectado, matiz que en español se pierde.

Ejemplo 2: Watashi wa obaasan ni shimareta.

Yo-p. tópico-abuela-partícula ni-verbo morir (pasiva)

Posible traducción: Se me murió la abuela.

En este otro ejemplo, el verbo morir en forma pasiva (shimareta) se combina con un tópico (watashi: yo) que no coincide con el sujeto lógico del verbo morir, sino con la persona afectada por la muerte. La traducción al español mediante la construcción llamada de dativo ético permite en este caso mantener de forma airosa los matices de afección de la persona implicada, presentes en la construcción japonesa.

Ejemplo 3 Yasumiga oosugide, yametemoraushikanakattanda

Descanso-p.nom.-mucho-conjunción-despedir (f.-te)-recibir

(forma de obligación)

"Como faltaba mucho, no tuve más remedio que despedirlo".

En el tercer ejemplo, extraído de una traducción de un manga, se expresa mediante la forma verbal de un verbo de recepción, como morau (recibir), adjunta a un verbo acabado en -te, que la acción indicada por este verbo es favorable para el receptor. De hecho, el uso de verbos de donación o recepción adjuntos al verbo principal permite expresar sutiles matices en japonés. Es imposible mantener este tipo de matices en español.

Ejemplo 4: Pasupooto o nakushite shimaimashita.

Pasaporte-acusativo- verbo perder (forma -te)- verbo terminar

Traducción posible: Perdí mi pasaporte 
Por su parte la construcción con el verbo en forma -te y el verbo shimaimasu (ejemplo 4) implica vergüenza o pesar en una situación embarazosa, matiz que no se conserva en la traducción.

\subsection{Decisiones relacionadas con el léxico}

En este apartado se examinan algunos problemas relacionados con el léxico, que son especialmente relevantes en la traducción entre lenguas de culturas muy distintas. En la exposición se aplicarán a japonés y español las aportaciones teóricas de Newmark (1992) desde el alemán. En primer lugar, resulta problemática la traducción de términos culturales que no existen en la lengua receptora, como se ejemplifica a continuación.

\section{Ejemplo 5: Amae}

El término japonés amae implica una relación en la que se espera algo de alguien con quien existe una relación de dependencia como la de un hijo hacia su madre. Sin embargo, este concepto no existe como tal en la cultura española. Si ya resulta difícil encontrar sinónimos perfectos entre lenguas, la referencia a conceptos que no existen en la cultura de llegada complica extremadamente la traducción, y esto es algo habitual entre culturas tan distintas como las que nos ocupan.

También son dificultosos los términos de la cultura de la lengua origen para objetos que no existen en la lengua término y que se pueden dejar sin traducir Es el caso del ejemplo siguiente.

Ejemplo 6: Katana

La katana es un tipo de sable japonés, y en Occidente generalmente se entiende que una katana es un sable japonés en general. Como el objeto referido no existe en la cultura española, pero aún así es conocido, puede ser conveniente dejar el término sin traducir.

Por otro lado, plantean problemas los términos a los que se les da diferente sentido en la lengua origen y la lengua meta. Es el caso por ejemplo de ni-kai, segundo piso literalmente, pero primero en la cultura japonesa.

\section{Ejemplo 7: Ni-kai}

Podemos citar finalmente expresiones que no tienen equivalente en español, como es el caso del ejemplo siguiente.

Ejemplo 8: Ohayoo gozaimasu

En español no se puede reflejar la diferencia entre ohayoo y ohayoo gozaimasu. Este saludo en ambos casos se traduce como buenos días, pero ohayoo gozaimasu 
implica formalidad y se usa por ejemplo para dirigirse a un superior. En los contextos japoneses la elección de la forma inmediatamente refleja la relación entre los usuarios.

Podrían citarse múltiples expresiones cuyo significado real es intraducible. Otro caso es el de la despedida Ittekimasu (literalmente Me voy y vengo) y su respuesta, Itterashai, expresiones empleadas cuando alguien se va de casa para volver luego. Citaremos también el saludo Ogenki desuka (literalmente ¿estás sano?) o la fórmula Itadakinasu, que se emplea antes de comer. En casos así las traducciones constituyen simples adaptaciones culturales.

\subsection{Decisiones comunicativas}

De acuerdo con Hatim y Mason (1990, 1997), la traducción constituye un proceso comunicativo que tiene lugar en un contexto social, por lo que no se la puede considerar aisladamente sino dentro de un contexto. Este estaría formado por tres dimensiones que configuran el texto y dan las claves para analizarlo, y que son la comunicativa, la pragmática y la semiótica. La dimensión comunicativa configura el registro y los dialectos, la pragmática configura la intención y la semiótica se refiere al sistema de valores de una cultura.

En este artículo nos limitaremos a presentar algunos ejemplos demostrativos de los problemas que pueden encerrar estas dimensiones para la traducción, empezando por la comunicativa. En japonés las diferencias de registro son muy marcadas y resulta comunicarse sin mostrar el tipo de relación que existe entre los hablantes. Estos matices se reflejan mediante la elección del estilo (cortés o llano), mediante el uso de honoríficos e incluso en la selección de los verbos (que reflejan el estatus del hablante y del interlocutor). Estos matices no se pueden mantener en la traducción al español, como se ve en el siguiente ejemplo:

Ejemplo 9: Aikido gi o itadakimashita

Aikido-traje-acusativo- recibir (de alguien superior) (pasado)

Traducción posible: He recibido un traje de aikido

En el ejemplo número nueve, la elección del verbo japonés implica que el objeto es recibido de parte de un superior, matiz que en la traducción al español se pierde.

Como ejemplo de fenómeno pragmático, citaremos las estrategias comunicativas, que, son muy distintas en ambas lenguas. El japonés emplea abundantemente los actos de habla indirectos para evitar una respuesta negativa o un rechazo, que ocasionaría un conflicto directo, lo que en esta cultura no se admite fácilmente. En español se emplea un estilo más directo, lo que debe tenerse en cuenta en la traducción. Reproducimos algunos ejemplos:

Ejemplo 10: Kangaete okimasu. Lo pensaré (En vez de "No")

Ejemplo 113: Sore wa chotto... Eso es un poco... (En vez de "No")

\footnotetext{
${ }^{3}$ Ejemplos extraídos de publicaciones manga.
} 
Ejemplo 12: A. Boku wa ii mono omoitsuita. B.-Soo desuka ne...

Traducción: A. Yo tengo una idea genial. B.-No sé yo...

La traducción de este último ejemplo ha sido tomada de una publicación manga. La respuesta de $\mathrm{B}$ es una expresión típica de confirmación (soo desuka), unida a la partícula $n e$, y se podría traducir como $A h$, ¿sí? Sin embargo, el traductor elige la frase No sé yo, que expresa directamente cierta oposición por parte de B, que en el texto original no queda tan patente.

Desde una perspectiva pragmática y semiótica en japonés encontramos multitud de partículas que responden a estrategias conversacionales que reflejan valores propios de una cultura concreta. Por ejemplo la partícula $n e$ indica sentimiento de empatía, insistencia en un juicio... La partícula yo indica al oyente algo que no sabía o bien implica insistencia en una opinión. La ausencia de estas partículas no cambia gramaticalmente el texto, pero este resulta frío sin ellas. Sin embargo, matices de este tipo son también difíciles de mantener en la traducción.

Ejemplo 13: Taihen desune. Qué pesado...

\section{Problemas lingüísticos en la traducción literaria del español al japonés}

La última sección se dedicará a problemas de la traducción literaria con origen lingüístico, tema que resulta especialmente conflictivo por su extrema complejidad. En efecto, la posibilidad de traducir literatura es un lugar común en los estudios de Traductología, y un problema recurrente en la bibligrafía. Sea cual fuere nuestra posición al respecto, lo cierto es que la traducción literaria es como mínimo extremadamente difícil, pues no solamente requiere la comunicación de unos contenidos, sino que la traducción debe conservar también el propósito estético del texto. Si la dificultad de traducir literatura es innegable en cualquier caso, lo cierto es que cuando la traducción se produce entre culturas, lenguas y códigos artísticos tan lejanos entre sí como son el japonés y el español, la problemática se acentúa hasta un grado máximo.

Buena parte de las dificultades de traducción de la literatura japonesa deriva de las peculiaridades lingüísticas del japonés. A continuación comentaré algunas de las principales dificultades en la traducción de obras literarias japonesas derivadas de las peculiaridades de la lengua. Para ello me basaré en las aportaciones de Donald Keene (1953), sin duda uno de los mayores especialistas occidentales en Literatura de Japón, con las matizaciones oportunas para el caso del español y consideraré también algunas ideas y ejemplos aportados por traductores españoles como Carlos Rubio y Vicente Haya.

La fonética japonesa se caracteriza por su simplicidad y por la escasa variedad silábica, pues la secuencia consonante-vocal es la más frecuente. Esa simplicidad fónica posibilita las homonimias. El gran número de palabras de sonido análogo permite la abundancia de juegos de palabras. Incluso en ocasiones se pueden mantener dos series de ideas diferentes, según los significados que se usen para los mismos 
sonidos. En el original se entienden simultáneamente ambos sentidos, especialmente porque la escritura ideográfica permite todas las lecturas. Sin embargo, inevitablemente, todas estas posibilidades se pierden en la traducción. En el siguiente ejemplo, comentado por V. Haya (2002), los ideogramas permiten un juego de ideas que pone en relación pares de contrarios como "mañana-noche" y "árbol-fuego", juego que no se puede mantener en la traducción.

Ejemplo 14. Uguisu ya / Cha-no-ki-batake no/ Asa-zuki-yo

Traducción: El ruiseñor canta:/En la plantación de té/la luna de una noche que se hace mañana.

También la prosodia del japonés está en consonancia con las características fónicas de la lengua. La simplicidad fónica haría de la rima un recurso demasiado fácil, por lo que el verso japonés se basa más bien en el número de sílabas. Así pues, se han distinguido dos formas poéticas principales, la tanka, de treinta y una sílabas divididas del siguiente modo: $5+7+5+7+7$ y el haiku, de diecisiete sílabas, que se reparten así: $5+7+5$. En la traducción a otras lenguas el mantenimiento de este recurso resulta problemático. Véase como ejemplo el haiku anterior.

Otra de las características de la poesía japonesa es su poder de sugestión. Este constituye una gran dificultad para el traductor y para el lector extranjero en general, porque fuera de la cultura japonesa no se conocen las zonas de sugestión. En ese sentido, los lugares comunes en la literatura japonesa no lo son en la española. En el ejemplo quince, la expresión mundo del rocío, empleada en las traducciones del famoso haiku de Issa relacionado con el tema de la muerte, constituye una traducción adecuada, pero aún así se pierde inevitablemente la referencia a la caducidad del mundo terrenal que encierra la imagen japonesa.

Ejemplo 15: Tsuyu no yo wa/ tsuyu no yo nagara/ sarinagara (Issa). Traducción: El mundo del rocío/ mundo este de rocío/y sin embargo... (Rodríguez Izquierdo)

El virtuosismo constituye otra característica que contrasta con la poesía occidental. En la cultura japonesa es frecuente que los poemas se creen sobre composiciones previas, con ligeros cambios sobre las mismas. Esto nos lleva a una presencia importante de la intertextualidad, que enriquece la experiencia del lector japonés, pero que no puede llegar al lector de la traducción en otra cultura. Véanse al respecto los dos haikus siguientes (ejemplo dieciséis), comúnmente citados. El segundo remite al primero y la justa captación de su belleza implica conocer aquél.

Ejemplo 16:

1 Tsurigane ni / Tomarite nemuru/ Kochoo ka na (Buson)

Traducción: En la campana del templo/descansa, dormida/una mariposa

2 Tsurigane ni/ Tomarite hikaru/ Hotaru ka na (Shiki)

Traducción: En la campana del templo descansa, reluciente, una luciérnaga

Por otro lado, hay que mencionar que el vocabulario específico en poesía no se corresponde entre las dos culturas. Por ejemplo, la palabra hanami remite al espec- 
táculo de la contemplación de los cerezos en flor. En español no existe no ya la palabra, ni siquiera el referente.

También los valores connotativos de las palabras y sus armónicos difieren. Así, en la cultura y en la tradición poética japonesa se considera hermoso el canto de la rana, no así en la española. Por otra parte, en la cultura española se valora la rosa frente a la flor del cerezo. La conservación de estos referentes en la traducción nos traslada a un escenario para nosotros más exótico, pero la impresión del lector de la traducción diferirá radicalmente de la del lector del original.

Otra característica de la lengua japonesa es su alta dependencia del contexto, facilitada por rasgos como su capacidad para la elipsis, la menor determinación, la ambigüedad formal de las palabras. En japonés no se señala género ni número en el sustantivo, ni persona en el verbo, los tiempos verbales pueden no precisarse... Estas características permiten una mayor variedad de traducciones.

Comentaremos al respecto tres ejemplos. En primer lugar, citaremos el haiku que quizá goce de mayor popularidad en Occidente: el conocido haiku de Bashoo, que ha motivado múltiples traducciones, precisamente porque el japonés permite interpretar más la forma. (Carece de artículo, las elipsis abundan, las categorías de las palabras se desdibujan...)

\section{Ejemplo 17: Furuike ya/ Kawazu tobikomu/ Mizu no oto}

Rubio (2005) traduce el texto y aporta otras traducciones que se reproducen a continuación, como botón de muestra ${ }^{4}$ de la ambigüedad del original. Son las de Fernando Rodríguez Izquierdo: "Un viejo estanque / el zambullirse una rana / ruido del agua", Antonio Cabezas: "Un viejo estanque. Se zambulle una rana, ruido del agua" y la suya: "El viejo estanque. Al saltar una rana, ruido del agua".

Véanse otros dos ejemplos, aportados por Haya (2002), para apreciar la rudimentariedad expresiva del original;

Ejemplo 18: Ama-gaeru/ bashoo-ni norite/soyogi keri (Kikaku).

Traducción palabra por palabra: Lluvia -rana /bananero-en-subiendo/tembla(r)-ba

Traducción: Minúscula ranita verde / al subir por el bananero /este temblaba

Ejemplo 19: Wakaba fuku/sara-sara-sara to/ame nagara Traducción palabra por palabra: Hojas -nuevas / soplar o brotar "sara-sara-sara"/lluvia mientras.

V. Haya (2002) aporta dos posibles traducciones, gracias a la simplicidad del original: "Durante la lluvia / se oía el soplar (del viento) sobre las hojas nuevas, / algo así como "srsrsr"; o "Durante la lluvia / el sonido del viento / y las hojas nuevas que brotan"

${ }^{4}$ C. Spinedi en El Rincón del Haiku recoge dieciséis versiones en español. 


\section{Conclusiones}

En estas páginas se ha realizado un repaso de las principales dificultades lingüísticas en la traducción del japonés al español, con especial énfasis en la traducción literaria. Este análisis no es exhaustivo, y debiera continuarse, habida cuenta de las grandes diferencias lingüísticas y culturales que separan a estas dos grandes lenguas. Del análisis se pueden extraer algunas conclusiones generales, que enumeramos a continuación.

Las diferencias lingüísticas entre estas dos lenguas no emparentadas causan problemas considerables en la traducción.

La gran distancia cultural se refleja en el léxico y en el ámbito contextual y hace difícil encontrar equivalencias traductoras, con lo que la traducción pierde matices.

La traducción poética resulta especialmente problemática por factores como los diferentes presupuestos estéticos, la imposibilidad de mantener los recursos poéticos basados en la forma o la imposibilidad de mantener todos los sentidos que conviven en el original japonés.

\section{Referencias bibliográficas}

Cabezas, A., La Literatura japonesa. Madrid: Hiperión 1990.

Díaz, A., «¿Qué Lingüística en la formación de traductores e intérpretes?», CLAC 20 (2004).

Hatim, B., I. Mason, Discourse \& the translator. London: Longman 1990.

Haya, V., El corazón del haiku: La expresión de lo sagrado. Madrid: Mandala 2002.

Ishijara, T., Gramática moderna de la lengua japonesa. Madrid: Edelsa 1965.

Keene, D., La Literatura japonesa. México: Fondo de cultura económica 1953.

Kuno, S., The Structure of the Japanese Language. Cambridge: MIT 1973.

Lanzaco, F., Los valores estéticos en la cultura clásica japonesa. Madrid: Verbum 2003.

Martin, S., A reference grammar of Japanese. New Haven: Yale University Press 1975.

Muñoz, R., Lingüística para traducir. Barcelona: Teide 1995.

Newmark, P., Manual de traducción. Madrid: Cátedra 1992.

Rubio, C.: Claves y textos de la literatura japonesa. Una introducción. Madrid: Cátedra 2007.

Shibatani, M., The Languages of Japan. Cambridge: Cambridge University Press 1990.

Spinedi, C., «El rincón del haiku». www.elrincondelhaiku.org

Takagi, K., Manual de lengua japonesa Madrid: UA 1996.

VVAA, Minna no Nihongo. Tokio: 3A Corporation 1999.

Watkins, M., «Reflexiones sobre la traducción de literatura japonesa al castellano». Cuadernos Canela 11 (1999): 33-49. 